\title{
Desempenho de trator-implemento na cana-de-açúcar em sistemas de plantio direto e convencional
}

\author{
José B. Duarte Júnior ${ }^{1}$, Ricardo F. Garcia ${ }^{2}$, Fábio C. Coelho ${ }^{2}$ \& Reynaldo T. Amim ${ }^{3}$
}

\begin{abstract}
RESUMO
Com este trabalho objetivou-se avaliar o desempenho de conjuntos mecanizados, através da patinagem, da velocidade do trator e da viabilidade de operação de plantio da cana-de-açúcar (Saccharum sp.) em sistema de plantio direto (SPD) e convencional (PC) sobre diferentes plantas de cobertura. O delineamento experimental utilizado foi o inteiramente casualizado (DIC), com três repetições, em esquema de faixas. Constituíram-se 24 tratamentos pelas combinações de parcelas: A1-PD da cana sobre crotalária; A2-PD da cana sobre feijão de porco; A3-PC da cana sobre mucuna preta incorporada; A4-PC da cana (testemunha); de subparcelas: B1-FORD 8430 DT + plantadora de duas linhas; B2-FORD 8430 DT + sulcador de três linhas; B3-FORD 5610 + sulcador de duas linhas; e de sub-subparcelas: C1 - 1ª marcha reduzida e C2 - $2^{\text {a }}$ marcha reduzida. Observou-se que as operações de sulcagem para posterior plantio manual ou sulcagem e plantio mecanizado da cana-de-açúcar em SPD sobre as plantas de cobertura sem serem manejadas anteriormente com roçadora ou rolofaca, foram possíveis e igualmente eficientes quando comparadas ao PC, portanto, é possível reduzir o tempo de implantação da cultura e os custos operacionais devido à diminuição do número de operações no SPD da cana-de-açúcar.
\end{abstract}

Palavras-chave: adubos verdes, conjuntos mecanizados, patinagem

\section{Tractor-implement performance in sugarcane under no-tillage and conventional planting systems}

\begin{abstract}
This research evaluated the performance of automated groups using slippage, tractor speed, and operational viability of planting sugarcane (Saccharum spp.) in no-tillage (SPD) and conventional (PC) systems under different plant coverings. The experimental design was completely randomized, using three repetitions in a split-split plot. There were twenty four treatments: A1-SPD the sugarcane on sunnhemp (Crotalaria juncea); A2-SPD the sugarcane on the jack bean (Canavalia ensiformis); A3-PC the sugarcane on incorporated black mucuna (Stilozobium aterrimum); A4-PC the sugarcane (control); sub-plots: B1-FORD 8430 DT + two row crop planter; B2-FORD 8430 DT + three lines furrow opener; B3-FORD 5610 + two lines furrow opener; and, sub-sub-plots: C1 - first reduced gear, and C2 - second reduced gear. The research verified that the slippage and speed results for furrow opening operations for subsequent manual or sugarcane planting operations in direct planting system on plant covering without previous management with cutter or roll-knife were possible and equally efficient when compared to the operational costs due to a reduction in the direct planting of sugarcane.
\end{abstract}

Key words: green fertilizers, automated groups, tire slippage

1 CCA/UNIOESTE, Rua Pernambuco, 1777, CEP 85960-000, Marechal Cândido Rondon, PR. Fone: (45) 3284-7878. E-mail: bduarte7@yahoo.com.br ${ }^{2}$ CCTA/UENF, Av. Alberto Lamego, 2000, Parque Califórnia, CEP 28013-602, Campos dos Goytacazes, RJ. Fone/Fax: (22) 2726-1426/2726-1549. E-mail: garcia@uenf.br; fcoelho@uenf.br

${ }^{3}$ Graduando em Agronomia, CCTA/UENF. E-mail: reyamim@click21.com.br 


\section{INTRODUÇÃO}

O Brasil, maior produtor de cana-de-açúcar (Saccharum sp.) do mundo, produz 440 milhões de toneladas por ano, sendo cerca de $85 \%$, ou seja, no Centro-Sul e $15 \%$ no Norte-Nordeste, resultando em mais de 14 bilhões de litros de álcool e 24 milhões de toneladas de açúcar (CONAB, 2005; Ministério da Agricultura, 2004a).

A região Norte do Estado do Rio de Janeiro se destaca como pólo do setor sucroalcooleiro, produzindo cerca de sete milhões de toneladas por ano, o equivalente a $2 \%$ da produção nacional (CONAB, 2005). A agroindústria canavieira é uma atividade tradicional, porém decadente nesta região. A crise do setor provocou o fechamento de algumas usinas nas últimas safras. Em 1980, havia dezessete usinas e uma destilaria autônoma em funcionamento, enquanto em 1997 apenas dez usinas e uma destilaria permaneceram em operação (Morgado \& Vieira, 1999); atualmente, são nove usinas e uma destilaria. A produtividade média da região gira em torno de $45 \mathrm{t} \mathrm{ha}^{-1}$, muito baixa, portanto, quando comparada com outras regiões sucroalcoleiras do Brasil e a média nacional de $74 \mathrm{t} \mathrm{ha}^{-1}$ (Morgado \& Vieira, 1999; Agrianual, 2002; Ministério da Agricultura, 2004b; CONAB, 2005).

De maneira geral, a cultura da cana-de-açúcar têm apresentado baixas produtividades em virtude da contínua utilização de métodos convencionais de manejo do solo (Morgado \& Vieira, 1999), nas quais se utilizam técnicas antigas, importadas na década de 70 de países de clima temperado que, em razão do inverno rigoroso com repetidas nevadas necessitava revolver o solo para expô-lo a radiação solar da primavera-verão a fim de facilitar o descongelamento da superfície do solo e, assim iniciar o cultivo das culturas de verão; Entretanto, essas características climáticas não são as mesmas do Brasil, onde predomina o clima tropical e subtropical necessitando-se de técnicas específicas ao próprio clima, solo etc (Corrêa, 1980).

O plantio direto é um sistema de manejo do solo que consiste no não revolvimento do solo, com exceção do sulco de plantio ou de semeadura, no uso da adubação verde para promover a ciclagem de nutrientes, fixação biológica de nitrogênio quando do uso de leguminosas e para formação e acúmulo de palhada na superfície do solo. É imprescindível, também, a rotação de culturas cuja utilização de espécies diferentes em relação a aspectos botânicos exploram o solo de forma diferenciada, proporcionam a diversidade fitossociológica, favorecendo o manejo integrado de plantas daninhas; em termos fitossanitários, quebra possíveis pontes biológicas de insetos e fitopatógenos, comuns na monocultura, facilitando o manejo integrado de pragas e doenças de plantas (Sá, 1998).

O SPD é o mais apropriado para a produção agrícola em clima tropical, haja vista que promove a melhoria da fertilidade do solo, reduzindo o número de operações e horas de máquinas e implementos agrícolas, mão-de-obra e o consumo de combustível; além disto, melhora as condições ambientais pela redução de erosão, compactação do solo e do uso de agroquímicos e pode, ainda interferir no rendimento da cultura. A médio e longo prazos, verifica-se redução nos custos de produção (Muzilli, 1981).
Atualmente, a maioria das operações agrícolas empregadas na instalação de uma cultura, desde o preparo do solo à colheita, pode ser mecanizada e apresenta grande eficiência e retorno econômico ao produtor, desde que bem conduzidas, empregando tecnologia e maquinário adequado, porém, há necessidade de que o conjunto trator e máquina agrícola estejam bem dimensionado para proporcionar elevada capacidade operacional, redução de custos e tempo. Espera-se, também, redução da compactação do solo e das operações agrícolas envolvidas e otimização da eficiência, tratória através do controle do índice de patinagem.

A operação de plantio requer, do trator utilizado, capacidade em desenvolver esforço para tracionar as máquinas e implementos agrícolas. Segundo a American Society of Agricultural Engineers (ASAE, 2003b), na transmissão de potência do motor para a barra de tração ocorrem perdas que, dependendo das condições de operação do trator, distribuição de peso sobre as rodas motrizes e tipo de acoplamento, podem atingir níveis bastante comprometedores. A American Society of Agricultural Engineers (ASAE, 2003b) apresentou um diagrama de estimativa de perda de potência nos diferentes setores do trator e em diversos tipos de tratores (4x2, 4x2 TDA, 4x4 e de esteiras) e condições de piso. A perda de potência disponível na barra de tração em relação à potência líquida no motor de tratores $4 \times 2$, pode variar de 22 a 51\% para piso de concreto e solos soltos, respectivamente, enquanto a perda de potência dos tratores 4x2 TDA pode variar de 22 a $42 \%$ para piso de concreto e solos soltos, respectivamente.

Conforme Standard D496.2 (ASAE, 2003a), a patinagem de um rodado de tração pode ser definida como a redução de deslocamento em determinada condição de piso comparada com uma condição específica, também chamada condição zero, onde se mede o rolamento do rodado em piso indeformável e em situação sem carga. A cobertura do solo interfere na capacidade do trator em desenvolver esforço para tracionar máquinas e implementos enquanto o tipo de cobertura pode causar mudanças de patinagem e na eficiência tratória (Gabriel Filho et al., 2004).

Através deste estudo propôs-se avaliar o desempenho de conjuntos mecanizados, utilizando-se a patinagem, a velocidade do trator e a viabilidade de operação de plantio da cana-de-açúcar em SPD e PC, sobre diferentes plantas de cobertura.

\section{MATERIAL E MÉTODOS}

A pesquisa foi realizada em área particular do Grupo Queiroz Galvão, na Fazenda Abadia, $3^{\circ}$ Subdistrito do $1^{\circ}$ Distrito de Campos, no município de Campos dos Goytacazes, na Região Norte do Estado do Rio de Janeiro, situada a

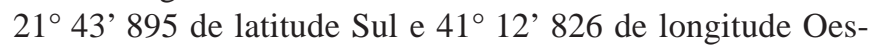
te e altitude de $12 \mathrm{~m}$ em relação ao nível do mar.

Utilizaram-se os seguintes conjuntos mecanizados: trator FORD 8430 DT 4x2 TDA, com plantadora de duas linhas DMB; trator FORD 8430 DT, com sulcador de três linhas e trator FORD $56104 x 2$, com sulcador de duas linhas. Os 
conjuntos foram avaliados em sistema de plantio direto sobre as plantas de cobertura crotalária e feijão de porco, e em sistema convencional, sobre mucuna preta incorporada e solo exposto revolvido. O solo predominante é o Cambissolo Ta eutrófico argiloso, com boa drenagem e textura argilo-siltosa, com 38, 52 e 10\% de argila, de silte e de areia total, respectivamente.

O delineamento experimental utilizado foi o inteiramente casualizado (DIC), com três repetições, em esquema de faixas. Construíram-se 24 tratamentos pelas combinações de parcelas: A1-PD da cana sobre crotalária; A2-PD da cana sobre feijão de porco; A3-PC da cana sobre mucuna preta incorporada; A4-PC da cana (testemunha); de subparcelas: B1-FORD 8430 DT + plantadora de duas linhas; B2-FORD 8430 DT + sulcador de três linhas; B3-FORD 5610 + sulcador de duas linhas; e de sub-subparcelas: C1 - $1^{\text {a }}$ marcha reduzida e $\mathrm{C} 2-2^{\mathrm{a}}$ marcha reduzida.

A patinagem foi calculada deslocando-se o trator em espaço predefinido, comparando-se o número de voltas do rodado motriz do trator em condição sem carga, em pista de concreto, e o número de voltas em condições de trabalho nas situações A1, A2, A3 e A4. Utilizaram-se as Eqs. 1 e 2 para o cálculo da patinagem e velocidade, respectivamente.

$$
\text { Patinagem }=\frac{\frac{\text { avanço sem carga }}{n^{\circ} \text { de voltas }}-\frac{\text { avanço com carga }}{n^{\circ} \text { de voltas }}}{\frac{\text { avanço com carga }}{n^{\circ} \text { de voltas }}}
$$

em que:

Patinagem - adimensional

avanço sem carga - espaço percorrido pelo trator em condição sem carga em pista de concreto, m

avanço com carga - espaço percorrido pelo trator em condições de trabalho, $\mathrm{m}$

$\mathrm{n}^{0}$ de voltas - número de voltas do pneu motriz no espaço percorrido correspondente, adimensional

$$
\mathrm{v}=\frac{\mathrm{e}}{\mathrm{t}}
$$

em que:

$$
\begin{aligned}
& \mathrm{v} \text { - velocidade, } \mathrm{m} \mathrm{s}^{-1} \\
& \mathrm{e} \text { - espaço, } \mathrm{m} \\
& \mathrm{t} \text { - tempo, } \mathrm{s}
\end{aligned}
$$

Os resultados obtidos de patinagem e velocidade foram submetidos a análise estatística, realizando-se a análise de variância (Teste F). Nos casos em que o " $F_{\text {calculado" foi maior }}$

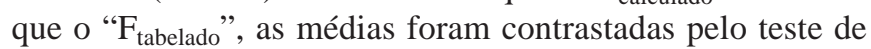
Tukey, em nível de 5\% de probabilidade (Gomes, 2000).

\section{RESULTADOS E DISCUSSÃO}

Analisando-se os resultados obtidos observou-se que, para a variável patinagem, os tratamentos das parcelas, subparcelas e sub-subparcelas foram diferentes entre si significativamente, segundo a Tabela 1. Os conjuntos em operação de plantio direto sobre a palhada de crotalária obtiveram con- dição favorável à patinagem dos rodados motrizes, que foi 34\% maior em comparação ao PC, porém no PD sobre crotalária não se observou diferença significativa em relação ao PD sobre feijão de porco nem ao convencional com mucuna preta incorporada; já a palhada de feijão de porco e o solo solto com a mucuna incorporada não favoreceram significativamente a patinagem dos rodados motrizes dos tratores quando comparado à patinagem no solo solto preparado convencionalmente.

No mesmo local da realização deste trabalho foram utilizados, também, a crotalária juncea, o feijão de porco e a mucuna preta, por Duarte Jr. et al. (2004), os quais constataram produção de 1,79, 1,26 e 1,01 kg m² de matéria seca, respectivamente; dessa maneira, verifica-se que a crotalária possivelmente obteve maior acúmulo de matéria seca em relação ao feijão de porco e mucuna preta, justificando assim o maior índice de patinagem observado. Gabriel Filho et al. (2004), também notaram maior patinagem em que a massa de matéria seca era maior corroborando com a relação de quanto maior a quantidade de matéria seca sobre o solo, maior também a patinagem dos rodados motrizes dos tratores.

Por outro lado, Mahl (2002) inferiu que, em condição de solo há quatro anos sob plantio direto, havia maior percentual de cobertura do solo que o convencional e a operação de semeadura sobre maior massa de palha se apresentou com menores índices de patinagem dos rodados do trator.

Tabela 1. Patinagem em operações de plantio de cana em diferentes manejos e plantas de cobertura submetidos a três conjuntos tratorimplemento e duas marchas de trabalho*

\begin{tabular}{lc}
\hline Manejo do solo e cobertura ${ }^{1}$ & Patinagem (\%) \\
PD sobre crotalária & $13,1 \mathrm{a}$ \\
PC sobre mucuna preta & $11,3 \mathrm{ab}$ \\
PD sobre feijão de porco & $10,8 \mathrm{ab}$ \\
PC (testemunha) & $9,8 \mathrm{~b}$ \\
\hline C.V. (\%) & 17,0
\end{tabular}

${ }^{*}$ Médias seguidas da mesma letra não diferem significativamente pelo teste de Tukey $(P<0,05)$ ${ }^{1} \mathrm{PD}$ - plantio direto e PC - preparo convencional do solo

Furlani et al. (2002) também observaram que, dentre outras variáveis, a patinagem dos rodados motrizes e o consumo de combustível foram maiores no preparo com escarificador em relação aos obtidos na semeadura direta com a palhada na superfície do solo.

A ASAE (1989) recomenda, para obtenção de máxima eficiência de tração, patinagem de 8-10\% em solos não mobilizados e de $11-13 \%$ em solos mobilizados, mas é importante salientar que os solos não mobilizados não têm palhada na superfície, ou seja, o solo está descoberto, razão por que se pode observar, pelos resultados obtidos de patinagem de rodados motrizes dos tratores utilizados, que na superfície do solo coberto com a palhada de feijão de porco com menor massa de matéria seca que a crotalária, a patinagem foi de aproximadamente $11 \%$, ou seja, pouco superior, portanto, à recomendada para a máxima eficiência de tração, mas o percentual de patinagem dos rodados motrizes dos tratores observados no solo solto do preparo 
convencional, estava abaixo da faixa recomendada e somente no solo solto com mucuna incorporada se, condicionou à patinagem dentro da faixa de $11-13 \%$ recomendada para máxima eficiência de tração em solos mobilizados, de acordo com a ASAE (1989). A patinagem reduzida observada se deve ao excesso de lastro no trator.

O conjunto FORD 5610 + sulcador apresentou 16,8\% de patinagem nos rodados motrizes do trator e maior valor quando comparado ao FORD 8430 DT + plantadora e FORD 8430 DT + sulcador com 10,9 e 6,1\%, respectivamente, conforme a Tabela 2. Independente da marcha utilizada e do tipo de manejo do solo empregado, o conjunto trator FORD 8430 DT + sulcador de três linhas apresentou patinagem aproximadamente $79 \%$ superior ao mesmo trator porém acoplado a plantadora de duas linhas.

Tabela 2. Patinagem em operações de plantio de cana em diferentes manejos e plantas de cobertura submetidos a três conjuntos tratorimplemento e duas marchas de trabalho*

\begin{tabular}{lc}
\hline Conjunto trator-implemento & Patinagem (\%) \\
FORD 5610 + sulcador de 2 linhas & $16,8 \mathrm{a}$ \\
FORD 8430 DT + sulcador de 3 linhas & $10,9 \mathrm{~b}$ \\
FORD 8430 DT + plantadora de 2 linhas & $6,1 \mathrm{c}$ \\
\hline C.V. (\%) & 17,0 \\
\hline * Médias seguidas da mesma letra não diferem significativamente pelo teste de Tukey $(\mathrm{P}<0,05)$
\end{tabular}

Observou-se, no estudo da interação conjunto x marcha, que o trator FORD 5610 + sulcador de duas linhas, na segunda marcha ( $3^{\mathrm{a}}$ reduzida) resultou em patinagem $16 \%$ superior quando comparada à primeira ( $2^{\mathrm{a}}$ reduzida), como se visualiza na Tabela 3. Os valores de patinagem observados nos outros conjuntos utilizados com duas marchas de trabalho não diferiram significativamente entre si.

Tabela 3. Patinagem em operações de plantio de cana em diferentes manejos e plantas de cobertura submetidos a três conjuntos tratorimplemento e duas marchas de trabalho*

\begin{tabular}{|c|c|c|}
\hline \multirow{3}{*}{ Conjunto } & \multicolumn{2}{|c|}{ Marcha do trator } \\
\hline & $1^{\mathrm{a}}$ reduzida & $2^{\mathrm{a}}$ reduzida \\
\hline & \multicolumn{2}{|c|}{ Patinagem (\%) } \\
\hline FORD 8430 DT + plantadora de 2 linhas & 6,2 Ca & $6,0 \mathrm{Ca}$ \\
\hline FORD 8430 DT + sulcador de 3 linhas & $11,2 \mathrm{Ba}$ & $10,6 \mathrm{Ba}$ \\
\hline FORD 5610 + sulcador de 2 linhas & $15,6 \mathrm{Ab}$ & $18,0 \mathrm{Aa}$ \\
\hline
\end{tabular}

* Médias na linha, seguidas de letras minúsculas diferentes, ou na coluna, seguidas de letras maiúsculas diferentes, são diferentes pelo teste de Tukey $(P<0,05)$

O conjunto trator FORD 8430 DT + plantadora de duas linhas apresentou-se com patinagem 45 e $43 \%$ inferior para as primeira e segunda marchas, respectivamente, ao trator FORD 8430 DT + sulcador de três linhas, conforme a Tabela 3, devido, provavelmente, ao fato do sulcador utilizar três elementos sulcadores enquanto a plantadora utiliza apenas dois elementos, caso em que o sulcador requer maior força de tração do trator quando comparado com à plantadora.

Sobre a mucuna o PC, proporcionou a maior velocidade, de $0,73 \mathrm{~m} \mathrm{~s}^{-1}$, quando comparado com a crotalária, que foi de $0,69 \mathrm{~m} \mathrm{~s}^{-1}$, mas semelhantes as demais coberturas, conforme visualizado na Tabela 4. A maior velocidade dos conjuntos foi notada sobre a mucuna preta incorporada. Os conjuntos obtiveram velocidade de operação 6\% superior sobre a mucuna em relação à crotalária, enquanto as velocidades de operação dos conjuntos sobre as coberturas feijão de porco, mucuna preta e o sistema convencional sem cobertura, não diferiram entre si significativamente; entretanto, Furlani et al. (2002) observaram que a velocidade de deslocamento foi maior no sistema de plantio direto e em preparo convencional do solo, o que acarreta também maior capacidade de campo efetiva nesses tratamentos.

Tabela 4. Velocidade de operações de plantio de cana em diferentes manejos e plantas de cobertura submetidos a três conjuntos máquinas e implementos e duas marchas de trabalho*

\begin{tabular}{lc}
\hline Manejo do solo e cobertura ${ }^{1}$ & Velocidade $\left(\mathbf{m ~ s}^{-1}\right)$ \\
PD sobre crotalária & $0,69 \mathrm{~b}$ \\
PC sobre mucuna preta & $0,73 \mathrm{a}$ \\
PD sobre feijão de porco & $0,71 \mathrm{ab}$ \\
PC (testemunha) & $0,72 \mathrm{ab}$ \\
\hline C.V. (\%) & 9,0 \\
\hline${ }^{*}$ Médias seguidas da mesma letra não diferem significativamente pelo teste de Tukey $(P<0,05)$ \\
1PD - plantio direto; PC - preparo convencional do solo
\end{tabular}

O conjunto trator FORD $8430 \mathrm{DT}+$ plantadora de duas linhas apresentou velocidade $8 \%$ superior ao trator FORD 8430 DT + sulcador de três linhas, conforme a Tabela 5, devido, provavelmente, ao fato do sulcador utilizar três elementos sulcadores enquanto a plantadora utiliza apenas dois elementos; neste caso, o sulcador requer maior força de tração do trator quando comparado à plantadora. Portanto, foi notória a correlação entre patinagem e velocidade dos conjuntos nas operações de plantio uma vez que ocorre decréscimo da velocidade, em conseqüência do aumento da patinagem.

Tabela 5. Velocidade de operações de plantio de cana em diferentes manejos e plantas de cobertura submetidos a três conjuntos máquinas e implementos e duas marchas de trabalho*

\begin{tabular}{lc}
\hline Conjunto de trator e implemento & Velocidade $\left(\mathrm{m} \mathrm{s}^{-1}\right)$ \\
FORD 5610 + sulcador de 2 linhas & $0,88 \mathrm{a}$ \\
FORD 8430 DT + sulcador de 3 linhas & $0,61 \mathrm{c}$ \\
FORD 8430 DT + plantadora de 2 linhas & $0,65 \mathrm{~b}$ \\
\hline C.V. $(\%)$ & 9,0 \\
\hline
\end{tabular}

${ }^{*}$ Médias seguidas da mesma letra não diferem significativamente pelo teste de Tukey $(P<0,05)$

Os conjuntos diferiram na interação conjunto x coberturas. O FORD $8430 \mathrm{DT}+$ sulcador apresentou a menor velocidade, que foi de $0,48 \mathrm{~m} \mathrm{~s}^{-1}$, conforme a Tabela 6; por outro lado, o conjunto FORD 5610 + sulcador obteve as maiores velocidades nos sistemas de manejo com diferentes coberturas, quando comparado aos demais conjunto; no entanto, este conjunto, trabalhando sobre a mucuna preta incorporada, apresentou velocidade 13 e $17 \%$ superior ao feijão de porco e crotalária, respectivamente, não diferindo do sistema convencional; além disto, o conjunto FORD 5610 + sulcador, 
Tabela 6. Velocidade de operações de plantio de cana em diferentes manejos e plantas de cobertura submetidos a três conjuntos máquinas e implementos e duas marchas de trabalho*

\begin{tabular}{lcc}
\hline \multirow{2}{*}{ Conjunto } & \multicolumn{2}{c}{ Marcha do trator } \\
\cline { 2 - 3 } & \multicolumn{1}{c}{$\mathbf{1}^{\mathrm{a}}$ reduzida } & $\mathbf{2}^{\mathrm{a}}$ reduzida \\
\cline { 2 - 3 } FORD $8430 \mathrm{DT}+$ plantadora de 2 linhas & $0,52 \mathrm{Bb}$ & $0,79 \mathrm{Ba}$ \\
FORD $8430 \mathrm{DT}+$ sulcador de 3 linhas & $0,48 \mathrm{Bb}$ & $0,73 \mathrm{Ba}$ \\
FORD 5610 + sulcador de 2 linhas & $0,64 \mathrm{Ab}$ & $1,11 \mathrm{Aa}$ \\
\hline C.V. $(\%)$ & \multicolumn{3}{c}{9,0} \\
\hline
\end{tabular}

* Médias na linha, seguidas de letras minúsculas diferentes, ou na coluna, seguidas de letras maiúsculas diferentes, são diferentes pelo teste de Tukey $(P<0,05)$

quando trabalhando sobre a crotalária, feijão de porco e sistema convencional, não apresentou diferença de velocidade.

Para o estudo de cada conjunto e cobertura, observou-se que o trator FORD 5610 + sulcador de duas linhas sobre a mucuna preta se apresentou com velocidade 17 e 13\% superior, respectivamente, às coberturas crotalária e feijão de porco, conforme a Tabela 7 , porém a velocidade foi semelhante ao sistema convencional sem utilização de adubo verde, enquanto, os demais conjuntos, individualmente, não apresentaram velocidades diferentes nas diversas coberturas utilizadas no trabalho.

Tabela 7. Velocidade de operações de plantio de cana em diferentes manejos e plantas de cobertura submetidos a três conjuntos máquinas e implementos e duas marchas de trabalho*

\begin{tabular}{|c|c|c|c|c|}
\hline \multirow{3}{*}{ Conjunto } & \multicolumn{4}{|c|}{ Cobertura } \\
\hline & $\begin{array}{c}\text { Crotalária } \\
\text { (PD) }\end{array}$ & $\begin{array}{l}\text { Feijão de } \\
\text { porco (PD) }\end{array}$ & $\begin{array}{c}\text { Mucuna } \\
\text { preta (PC) }\end{array}$ & Convencional \\
\hline & \multicolumn{4}{|c|}{ Velocidade $\left(\mathrm{m} \mathrm{s}^{-1}\right)$} \\
\hline $\begin{array}{l}\text { FORD } 8430 \text { DT + } \\
\text { plantadora de } 2 \text { linhas }\end{array}$ & 0,65 Ba & 0,66 Ba & $0,64 \mathrm{Ba}$ & $0,66 \mathrm{Ba}$ \\
\hline $\begin{array}{l}\text { FORD } 8430 \text { DT + } \\
\text { sulcador de } 3 \text { linhas }\end{array}$ & $0,59 \mathrm{Ba}$ & $0,61 \mathrm{Ba}$ & $0,60 \mathrm{Ba}$ & $0,62 \mathrm{Ba}$ \\
\hline $\begin{array}{l}\text { FORD } 5610 \text { + sulcador } \\
\text { de } 2 \text { linhas }\end{array}$ & $0,82 \mathrm{Ab}$ & $0,85 \mathrm{Ab}$ & $0,96 \mathrm{Aa}$ & 0,88 Aab \\
\hline C.V. (\%) & \multicolumn{4}{|c|}{9,0} \\
\hline
\end{tabular}

${ }^{*}$ Médias na linha, seguidas de letras minúsculas diferentes, ou na coluna, seguidas de letras maiúsculas diferentes, são diferentes pelo teste de Tukey $(P<0,05)$

Com relação à velocidade do conjunto FORD 8430 DT + plantadora em comparação ao FORD 8430 DT + sulcador de três linhas, não houve diferença significativa, como se visualiza na Tabela 7.

$\mathrm{O}$ aumento da força requerida não causou diferença significativa de velocidade entre o conjunto trator FORD 8430 DT + plantadora e FORD 8430 DT + sulcador três linhas, conforme Tabela 8; além disto, verificou-se que a velocidade em segunda marcha foi 73, 52 e 52\% superior para os conjuntos FORD 5610 + sulcador de duas linhas, FORD 8430 DT + plantadora e FORD 8430 DT + sulcador de três linhas, respectivamente, em relação à primeira marcha utilizada.

Verifica-se que, de modo geral o conjunto FORD 5610 + sulcador apresentou elevada patinagem de seus rodados, devido ao baixo lastro, o que pode ocasionar aumento de consumo de combustível, redução da eficiência tratória e capacidade de campo e cisalhamento do solo seguido de
Tabela 8. Velocidade em operações de plantio de cana em diferentes manejos e plantas de cobertura submetidos a três conjuntos tratorimplemento e duas marchas de trabalho*

\begin{tabular}{lcc}
\hline \multirow{2}{*}{ Conjunto } & \multicolumn{2}{c}{ Marcha do trator } \\
\cline { 2 - 4 } & \multicolumn{1}{c}{$\mathbf{1}^{\mathrm{a}}$ reduzida } & $\mathbf{2}^{\mathrm{a}}$ reduzida \\
\cline { 2 - 4 } FORD $8430 \mathrm{DT}+$ plantadora de 2 linhas & $0,52 \mathrm{Bb}$ & $0,79 \mathrm{Ba}$ \\
FORD $8430 \mathrm{DT}+$ sulcador de 3 linhas & $0,48 \mathrm{Bb}$ & $0,73 \mathrm{Ba}$ \\
FORD 5610 + sulcador de 2 linhas & $0,64 \mathrm{Ab}$ & $1,11 \mathrm{Aa}$ \\
\hline C.V. $(\%)$ & \multicolumn{3}{c}{9,0} \\
\hline
\end{tabular}

* Médias na linha, seguidas de letras minúsculas diferentes, ou na coluna, seguidas de letras maiúsculas diferentes, são diferentes pelo teste de Tukey $(P<0,05)$

compactação superficial do solo. Em outra condição oposta, observou-se reduzida patinagem para o conjunto FORD 8430 DT + plantadora que estava com peso excessivo o que pode ocasionar compactação do solo, desgaste prematuro de partes do trator como motor, pneus, mancais e rolamentos, além de baixa eficiência tratória; Notou-se, também, situação ideal de patinagem para trabalho com o conjunto FORD 8430 DT + sulcador, que está na faixa de 8 a 10\% considerando-se o solo firme, evidenciando que este conjunto estava bem dimensionado no que se refere ao lastro e a força de tração.

Verificou-se que as operações de sulcagem para posterior plantio manual ou sulcagem e plantio mecanizado da canade-açúcar em sistema de plantio direto sobre as plantas de cobertura sem serem manejadas anteriormente com roçadora ou rolo-faca, foram possíveis e igualmente eficientes quando comparadas ao sistema de plantio convencional; portanto, é possível reduzir o tempo de implantação da cultura e os custos operacionais, devido à diminuição de operações no plantio direto da cana-de-açúcar.

\section{CONCLUSÕES}

1. O conjunto FORD 5610 + sulcador apresentou elevada patinagem de seus rodados, enquanto o conjunto FORD 8430 DT + plantadora apresentou reduzida patinagem.

2. A patinagem do conjunto FORD 8430 DT + sulcador apresentou-se na faixa ideal de 8 a $10 \%$, considerando-se o solo firme.

3. O conjunto FORD 5610 + sulcador obteve as maiores velocidades nos sistemas de manejo com diferentes coberturas.

4. As operações de sulcagem para plantio manual ou sulcagem e plantio mecanizado da cana-de-açúcar, em SPD sobre palhada de crotalária e de feijão de porco, sem serem manejadas com roçadora ou rolo-faca, foram possíveis e igualmente eficientes como no PC; portanto, dá-se redução do tempo de implantação da cultura e dos custos operacionais devido ao menor número de operações no SPD da cana-de-açúcar.

\section{AGRADECIMENTOS}

A UENF, pelo empréstimo de maquinário; a FAPERJ, pelo apoio financeiro; ao Grupo Queiroz Galvão e aos funcionários da Fazenda Abadia: Willy Pedro, João Batista, Amaro 
Viana, Juarez, Victor, Amália, Aladi, Gerson, Daniel, Magno, Marcelo, Fábio Jr., Flávio, Amaro Ball, Wilson, Jorge, Bartolomeu, Jonas, José Faria, Amaro Braga, Wilia, Joaci e Adilson (in memoriam) pelo empréstimo da área de pesquisa, tratores e apoio operacional.

\section{LITERATURA CITADA}

Agrianual 2002. Anuário da Agricultura Brasileira. São Paulo: Argos Comunicação, 2002. 545p.

ASAE - American Society of Agricultural Engineers. Agricultural tractor test code. St. Joseph: ASAE Standards S209.5. 1989. p.44-48.

ASAE - American Society of Agricultural Engineers. Agricultural machinery management. St. Joseph: ASAE Standards D496.2. 2003a. p.367-372.

ASAE - American Society of Agricultural Engineers. Agricultural machinery management data. St. Joseph: ASAE Standards D497.4. 2003b. p.373-380.

CONAB. Companhia Nacional de Abastecimento. Revista Indicadores da Agropecuária, ano XIV, n.9, p.8, 2005.

Corrêa, L. A. Plantio direto em milho. Informe Agropecuário, ano 6, n.72, 1980, p.35-38.

Duarte Jr., J. B.; Coelho, F. C.; Lima, E. A. de. Avaliação da produção de matéria seca de adubos verdes para utilização em sistema de plantio direto de cana-de-açúcar, em Campos dos Goytacazes - RJ. In: Encontro de Iniciação Científica, 9, Mostra de Pós-graduação, 4, e Mostra de Extensão, 2, 2004, Campos dos Goytacazes. Resumos ... Campos dos Goytacazes: UENF, 2004. CD Rom.
Furlani, C. E. A.; Gamero, C. A.; Levien, R.; Lopes, A.; Silva, R. P. da. Semeadora-adubadora de fluxo contínuo: Desempenho operacional em função de diferentes condições de preparo e cobertura do solo. Engenharia Agrícola, v.22, n.1, p.60-67, 2002.

Gabriel Filho, A.; Silva, S. de L.; Modolo, A. J.; Silveira, J. C. M. da. Desempenho de um trator operando em solo com diferentes tipos de cobertura vegetal. Engenharia Agrícola, v.24, n.3, p.781-789, 2004.

Gomes, F. P. Curso de estatística experimental. 14.ed., Piracicaba: Nobel, 2000. 467p.

Mahl, D. Desempenho de semeadoras adubadoras de milho (Zea mays L.) em sistema de plantio direto. Botucatu: UNESP, 2002. 160p. Dissertação Mestrado

Ministério da Agricultura. <http://www.agricultura. gov.br/ pls/portal/docs/PAGE/MAPA/ESTATISTICA/ PRODUCAO/ESTOQUES_CANA_BR_US_PTB.PDF $>$. 2004a. 07 Mai. 2004.

Ministério da Agricultura. <http://www.agricultura. gov.br/pls/ portal/docs/PAGE/MAPA/ESTATISTICAS/AGRICULTURA _EM_NUMEROS_2003/3.1.02.F.XLS > 2004b. 13 Ago. 2004 .

Morgado, I. F.; Vieira, J. R. Tecnologias canavieira nas regiões Norte Fluminense e sul do Espírito Santo. Campos dos Goytacazes: UFRRJ, 1999. 61p. Boletim Técnico

Muzilli, O. Princípios e perspectivas de expansão. Londrina: Plantio direto no Paraná, IAPAR , 1981. 244p. Circular

Sá, J. C. de M. Reciclagem de nutrientes dos resíduos culturais, e estratégia de fertilização para produção de grãos no sistema plantio direto. In: Seminário sobre o Sistema Plantio Direto na UFV, 1, 1998, Viçosa. Resumos... Viçosa: DFT/UFV, 1998. 143p. 